\title{
Las presentaciones multimedia en el ámbito científico
}

\author{
Por Norelkys Espinoza Matheus y Ángel G. Rincón García
}

Norelkys Espinoza Matheus, ingeniero de sistemas, magíster scientiae en ingeniería de control y automatización. Profesor asistente en el Depto. de Investigación, Facultad de 0 dontología, Univ. de Los Andes, Mérida, Venezuela. Profesor meritorio nivel III (Conaba) Convocatoria 2002, premio otorgado por la Comisión $\mathrm{N}$ acional del Sistema para el Reconocimiento de Méritos a los Profesores de las Universidades $\mathrm{N}$ acionales Venezolanas, Fapuv-CNU. Programa de Estímulo al Investigador (PEI) Convocatoria 2003, premio otorgado por la Univ. de Los Andes. Coordinador del Grupo Multidisciplinario de Investigaciones en 0 dontología, adscrito al Consejo de Desarrollo Humanístico, Científico y Tecnológico (Cdcht) de la Univ. de Los A ndes. Ha publicado en revistas arbitradas e indizadas, tanto venezolanas como

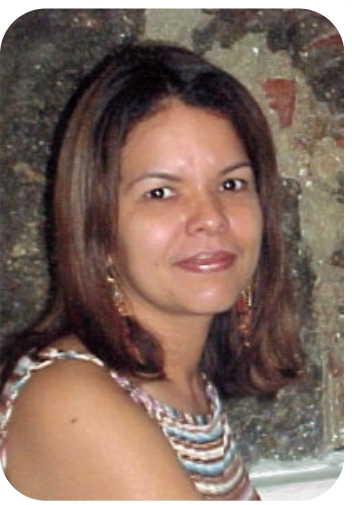
internacionales, acerca de la aplicación de las nuevas tecnologías en la educación, la lectura y la escritura, la salud, la enseñanza de la investigación y en la formación integral del docente universitario. Ha participado como ponente en numerosos congresos nacionales e internacionales.

Ángel Gabriel Rincón García, médico cirujano por la Univ. de Los Andes, Mérida, Vene-

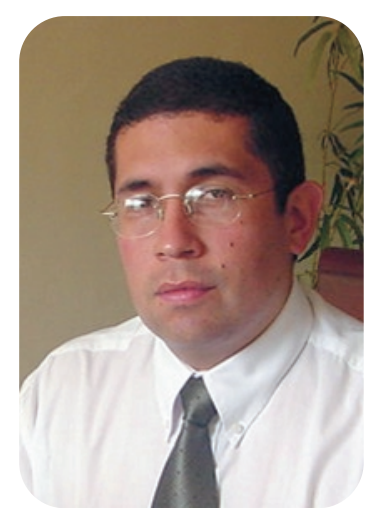
zuela. Estudios de postgrado en ginecología y obstetricia, ocupando primer lugar de promedios de notas en el curso. En 2000 realizó la sub-especialidad de cirugía endoscópica en Barcelona, España, donde fue profesor de talleres de práctica y participó en el equipo quirúrgico. Es miembro de: Colegio de M édicos del Estado M érida, Federación M édica Venezolana, Asociación Panamericana de Anatomía, Sociedad Española de Citología, Sociedad de Endoscopia e Imagenología de Iberoamérica y titular de la Sociedad Venezolana de 0 bstetricia y Ginecología. Desde 2001 está adscrito al Depto. de Investigación de la Fac. de 0 dontología de la Univ. de Los Andes. Ha publicado en revistas nacionales e internacionales sobre su especialidad médica, y sobre la enseñanza de la investigación. Como médico e investigador ha sido ponente en múltiples congresos científicos.
Resumen: El creciente volumen de información científica y su velocidad de producción han incentivado a los investigadores a participar en diferentes eventos, tanto nacionales como internacionales, con el propósito de divulgar y compartir el conocimiento. En los mismos se presentan, en cortos períodos de tiempo, los resultados de sus investigaciones. Las nuevas tecnologías multimedia, con la integración de sonidos, gráficas, vídeo, texto y animación, representan un recurso para el expositor que procura transmitir la información de manera visual y no sólo verbalmente, y que de ser usado adecuadamente, facilitaría a la audiencia una mejor comprensión del mensaje que desea comunicar. Presentamos en esta revisión los distintos aspectos a considerar al preparar una presentación oral, entre los cuales están: perfil de la audiencia, propósito de la presentación, lapso de tiempo y los puntos más importantes del trabajo, así como la elección del software y el hardware. Finalmente concluimos que la presentación oral de una investigación es tan importante como el informe escrito, y que su correcta planificación garantiza el éxito en la difusión del conocimiento científico.

Palabras clave: Presentación electrónica, Multimedia, Diapositivas, Expositor, Audiencia.

\section{Title: Multimedia presentations in a scientific context}

\begin{abstract}
The growing volume of scientific information and its high rate of production serve as an incentive for researchers to participate in congresses, symposia, etc, both nationally and internationally, with the goal of communicating scientific knowledge. In these events numerous reports and research results are presented in a brief period of time. Currently multimedia technology —integrating sound, images, video, text and animation-is used as a tool by speakers for transmitting information visually, as well as verbally. Used properly, such tools contribute to the audience's understanding of the message being delivered.

This article covers the different points to be considered when preparing an oral presentation, in order to facilitate the dissemination of scientific results. These points include audience profile, purpose of the presentation, time allotted, highlights of the research project, and choice of software and hardware. The authors conclude that oral presentations of research results are as important as the written report, and proper planning and use of multimedia resources will enhance the possibilities for scientific communication.
\end{abstract}

Keywords: Electronic presentations, Multimedia, Slides, Speakers, Audience. 


\section{Nuevos seminarios de presentación online}

Ofrecemos seminarios de presentación online de sus productos de automatización de bibliotecas, gestión e i ntegración de recursos electrónicos y gestión de co lecciones multimedia.

Durante los meses de Septiembre, Octubre y Noviembre realizaremos seminarios periódicos completamente gratuitos donde se mostrarán las principales características de MetaLib, SFX, Verde y DigiTool.

\begin{tabular}{|l|l|}
\multicolumn{2}{|l|}{ Septiembre } \\
\hline Dia $21,11 \mathrm{~h}$ & MetaLib \\
\hline Dia 23,11h & SFX $\sqrt{3}$ \\
Dia $28,11 \mathrm{~h}$ & MetaLib \\
\hline Dia $30,11 \mathrm{~h}$ & SFX $\sqrt{3}$ \\
\hline
\end{tabular}

\section{Seminarios impartidos}

MetaLib: Gestión Integral de Recursos SFX: Más que un servidor de enlaces Verde: Electronic resources management Digitool. Catalogación, preservacion y difusión de fondos digitales

\begin{tabular}{|l|l|}
\hline \multicolumn{2}{|l|}{ Octubre } \\
\hline Dia 12, 11h & MetaLib \\
\hline Dia 12, 12:30h & Verde \\
\hline Dia 14, 11h & SFX v3 \\
\hline Dia 14, 12:30h & Verde \\
Dia 19, 11h & Verde \\
Dia 21, 11h & Verde \\
Dia 26, 11h & Verde \\
\hline Dia 28,11h & Verde \\
\hline
\end{tabular}

\begin{tabular}{|l|l|}
\hline \multicolumn{2}{|l|}{ Noviembre } \\
\hline Dia 2, 11h & Verde \\
\hline Dia $4,11 \mathrm{~h}$ & Verde \\
Dia $9,11 \mathrm{~h}$ & Digitool \\
\hline Día 16,11h & Digitool \\
\hline Dia $23,11 \mathrm{~h}$ & Digitool \\
\hline Dia $30,11 \mathrm{~h}$ & Digitool \\
\hline
\end{tabular}

Además, también ofrecemos demostraciones de los principales recursos informativos que puede adquirir a traves de nosotros: Oxford Reference Online Premium (OUP). Country Reports (EIU), Factiva (Proquest), LiOn (Proquest), Sage Full Text Collections (CSA) y Kluwer Online Reference Works (Springer-KJuwer).

\begin{tabular}{|l|l|}
\hline \multicolumn{2}{|l|}{ Septiembre } \\
\hline Dia 22, 10h & Oxford Reference Online Premium \\
\hline Dia 23,10h & Oxford Reference Online Premium \\
Dia 29, 10h & Sage Full Text Collections \\
\hline Dia 30,10h & Sage Full Text Collections \\
\hline
\end{tabular}

\begin{tabular}{|l|l|}
\hline \multicolumn{2}{l|}{ Octubre } \\
\hline Dia 06, 10h & Kluwer Online Reference Works \\
\hline Dia 07,10h & EIU Viewswire \\
Dia 13,10h & EIU Viewswire \\
Dia 14, 10h & FACTIVA \\
\hline Dia 20,10h & Sage Full Text Collections \\
\hline Dia 21, 10h & LiOn \\
\hline Dia 27, 10h & Oxford Reference Online Premium \\
\hline Día 28, 10h & Kluwer Online Reference Works \\
\hline
\end{tabular}

Los cursos se realizan a través de la plataforma de comunicación Interwise que permite imp artir seminarios y cursos virtuales, asi como realizar reuniones a través de la red.

Puede obtene $r$ más información sobre los cursos en:

\section{info@greendata.es}

Tuset 19, 20-7 08006 - Barcelona Tel: 902118398

Fax: 932021077
Jaen, 15

28020 - Madrid Tel: 902196032

Fax: 915711952 


\section{Introducción}

El creciente volumen de información científica y su velocidad de producción han incentivado a los investigadores a participar en diferentes eventos, tales como congresos, simposios, coloquios, nacionales e internacionales, con el propósito de divulgar y compartir el conocimiento. En ellos se muestran los resultados de investigaciones mediante presentaciones orales, ponencias, posters y carteles, y el reto es comunicar en un corto período de tiempo la mayor cantidad de información posible, resaltando los aspectos más importantes de lo investigado.

Las distintas modalidades de presentación de un trabajo científico van desde la utilización de pizarra, rotafolio, transparencias y diapositivas en carrusel, hasta el uso de diapositivas multimedia, siendo esta última una de las tecnologías aplicadas a la divulgación de la ciencia. Sin embargo, el medio siempre debe ser seleccionado por el investigador de acuerdo con la naturaleza del tema a desarrollar, a fin de que la presentación sea lo más didáctica posible.

Además de facilitar la transmisión de la información, el uso del multimedia le permite al investigador, o expositor en este caso, una comprensión más viable del mensaje por parte de la audiencia, consolidando de esta forma la credibi- lidad del expositor, que es debido a la estimulación de los sentidos que el multimedia proporciona a fin de mantener a la audiencia atenta.

En este sentido, al presentar los resultados de una investigación debe considerarse una serie de aspectos:

-Perfil de la audiencia, ya que si es conocido se responderá mejor a sus necesidades.

-Propósito de la presentación.

—Lapso de tiempo estipulado para el acto.

-Cómo contemplar los puntos más importantes del trabajo de investigación para estructurar los contenidos y ofrecer a la audiencia una exposición didáctica y de calidad científica.

Una vez hecho esto, se elaboran las diapositivas multimedia, que serán usadas como apoyo a la presentación, y se eligen el hardware y el software.

\section{El enfoque multimedia}

El multimedia estimula la vista y el oído de quienes conformen la audiencia. Tufte (1990) citado en Poole (2001) considera que la vista es el sentido más importante para el cerebro en la adquisición de datos y explica la razón por la que las metodologías más eficaces sobre presentaciones son las que procuran transmitir la información visual y no sólo la verbal: la persona que ve puede absorber los datos al escanearlos a una velocidad y en un orden que se ajustan de manera natural a su estructura mental.

«Las técnicas
multimedia, con
la integración de
sonidos, gráfi-
cas, vídeo, texto
y animación,
son un impor-
tante recurso
para el expositor
que procura
transmitir la in-
formación de
manera visual y
no sólo verbal-
mente»

Por otro lado, el citado autor señala que el habla por sí sola no es tan fácil de asimilar como cuando se acompaña de imágenes visuales. La palabra requiere un mayor esfuerzo para su comprensión porque se transmite una cantidad menor de información a una velocidad menor, lo cual requiere una mayor concentración y capacidad de extrapolación de quien escucha.

Por eso en la presentación de trabajos científicos es esencial la utilización de un enfoque multimedia que implica, según Cabero y Gisbert (2002) la interacción y combinación didáctica de los mismos para alcanzar objetivos preestablecidos, y no la mera suma de medios.

Las aplicaciones multimedia en el ámbito científico, utilizadas como instrumento de apoyo, facilitan la comunicación siempre y cuando exista una estimulación sensorial apropiada, que sea atractiva para el oyente, y no una sobreestimulación, extremo éste que según Cabero y Gisbert (2002) dificulta la capacidad de abstracción, por lo que se recomienda cuidar 


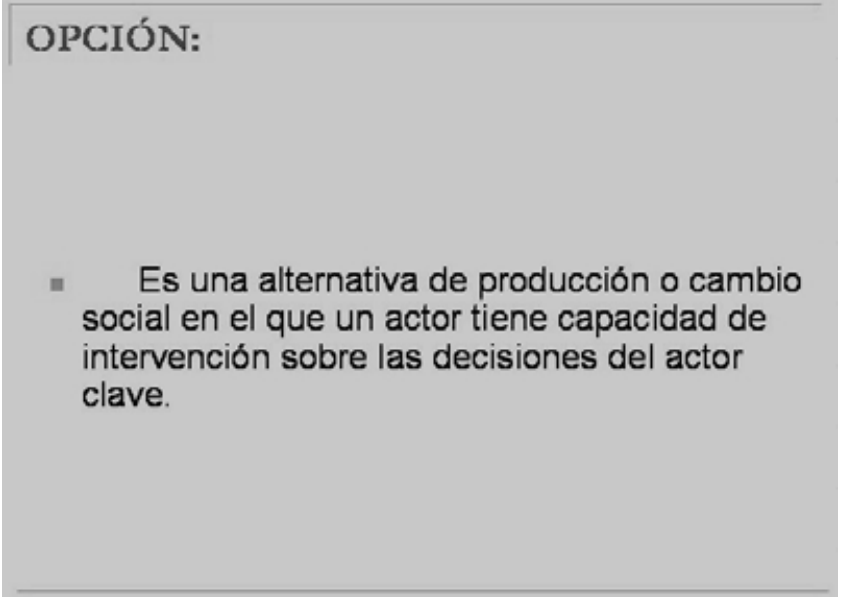

Gráfico 1B: Diapositiva en la que se presenta de forma correcta la información del gráfico 1A

ciertos planteamientos en el diseño de las diapositivas.

\section{Aspectos a considerar en el diseño}

Las diapositivas deben presentar la información de forma sencilla, clara, atractiva e innovadora, con el fin de mantener la atención de los oyentes. Para ello es conveniente utilizar los medios de que se dispone (sonidos, gráficas, animación, vídeo y texto) y evitar la saturación del receptor. Al respecto, St.-Pierre y Kustcher (2001) señalan que se debe evitar incluir muchos elementos visuales en la diapositiva para no confundir a la audiencia; más bien es recomendable aligerar la densidad de la información en cada pantalla para que se distinga con claridad.

Se pueden utilizar diferentes tipos de animaciones, siempre que no ofrezcan el peligro de distraer al oyente de lo significativo. Tampoco es conveniente que la presentación tenga muchas imágenes, ya que se corre el riesgo de que sea demasiado extensa (y además ocupe muchos bytes de espacio en disco y deje de ser transportable). Podría ocurrir, así mismo, un problema adicional de lentitud ocasionada al tener que manejar gran cantidad de información la memoria principal del sistema.

En cuanto al texto, St.-Pierre y Kustcher (2001) recomiendan eslo que se refiere a los colores y ti- poco iluminado. Por el contrario en sitios muy iluminados se recomienda la utilización de fondos claros con letras oscuras.

En relación con las fuentes, se debe utilizar el mismo tipo y tamaño para todos los títulos (p. ej., de 32 puntos), subtítulos (30, en caso de ser necesarios) y contenidos (24 a 28).

Todas las diapositivas, a excepción de la primera que corresponde a la presentación del tema, deben estar compuestas por:

1. Un título: en el extremo sutructurar la información en bloques un texto largo en pantalla, sin estructura aparente, desanimará a los asistentes; esto se debe a que leer en pantalla es mucho más lento que leer en papel.

Se debe tender a la uniformidad del formato usando una plantilla de diseño y la misma combinación de colores a lo largo de la presentación, así como la misma ubicación y clase de fuente, tanto en po, como al tamaño. Se debe cuidar que exista contraste - aunque no excesivo- entre el fondo y el texto, a fin de que no se afecte la legibilidad de este último y no provoque fatiga visual.

Con respecto al color se recomienda el uso de fondos oscuros con letras claras si la presentación se realiza en un ambiente oscuro o perior de la misma, en tamaño 32 , preferiblemente con un color de letra distinto al utilizado para el contenido de las diapositivas, de manera que resalte.

2. Contenido: desarrollo del punto al que hace referencia el título. Se recomienda que el contenido sea presentado en a) un párrafo de 5 a 6 líneas, b) dos párrafos de 3 líneas o c) tres párrafos de dos líneas, pero siempre debe estar separado por lo menos un centímetro del título (ver gráficos 1A, 1B y 1C). En caso de que en la diapositiva se utilicen imágenes y/o tablas, pueden ubicarse a un lado del texto. En caso de que se desee utilizar diapositivas que únicamente presenten la imagen o tabla, deben ser explicadas minuciosamente por el expositor, y en todo caso, se debe hacer referencia a la fuente original (me-

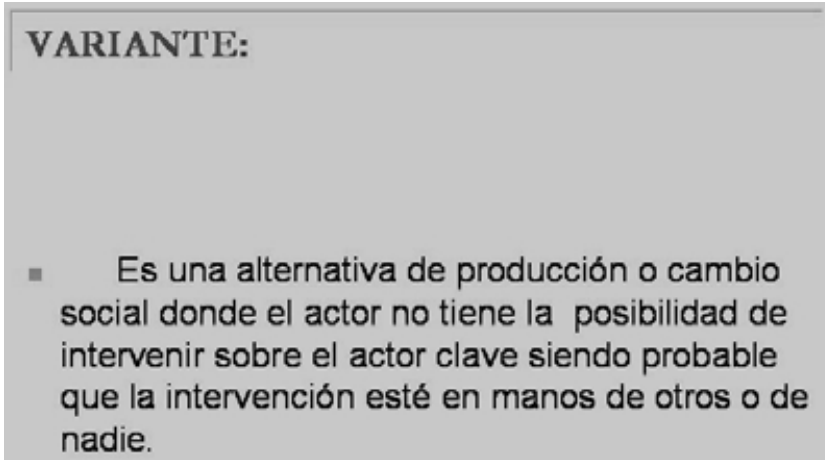

Gráfico 1C: Diapositiva en la que se presenta de forma correcta la información del gráfico $1 \mathrm{~A}$ 
diante un sistema de referencia, como por ejemplo, APA, Vancouver u otro) utilizando un cuadro de texto al pie de la misma con un tamaño de fuente de 12 ó 14 puntos.

\section{«El uso del mul- timedia permite a la audiencia una mejor com- prensión del mensaje del ex- positor»}

La presentación multimedia debe incluir los siguientes aspectos en orden sucesivo:

1. Tema: debe ir en la parte superior el nombre de la institución a la que pertenece el investigador, en la parte intermedia el título del trabajo y en la parte inferior el nombre del autor (ver gráficos $2 \mathrm{~A}$ y 2B).

2. Esquema: se escribirá en la parte superior de la diapositiva la palabra Esquema. Seguidamente se mostrarán todos los títulos o secciones principales que integran la presentación multimedia en el orden en que serán expuestos (ver gráficos $3 \mathrm{~A}$ y $3 \mathrm{~B}$ ).

3. Introducción: debe situarse en la parte superior de la diapositiva la palabra Introducción. Se recomienda que sea breve y clara y que permita a la audiencia formarse una idea general acerca del tema. El expositor debe incluir el

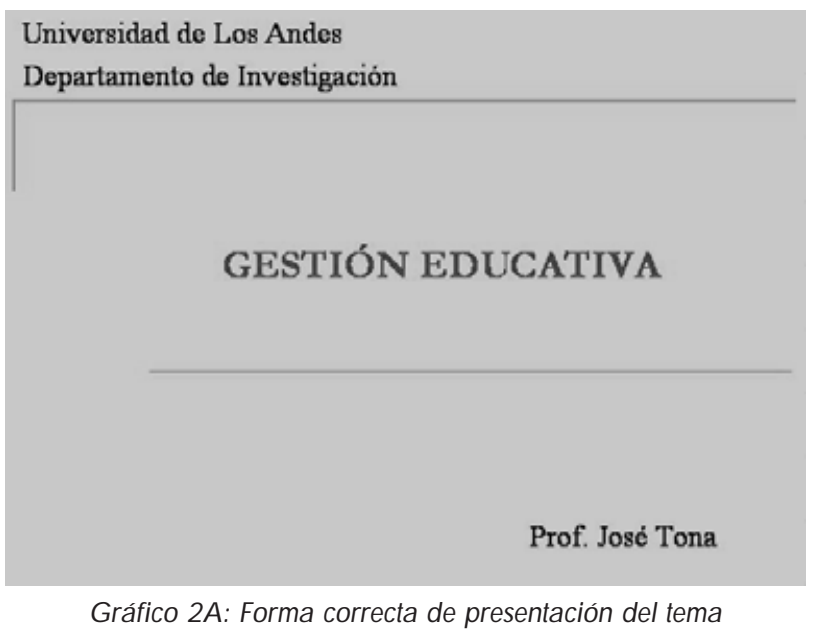

planteamiento de problema, la justificación e importancia y los objetivos que guiaron el estudio.

4. Desarrollo del tema: utilizar tantas diapositivas como sean necesarias para tratar los aspectos principales de acuerdo con el tiempo disponible, y escribir claramente en el extremo superior de la diapositiva un título que sea representativo. Se debe ser económico en el lenguaje, siendo los contenidos seleccionados los más significativos del trabajo de investigación. Realizar una exposición clara, sencilla y progresiva, evitando las redundancias, y adaptados a la audiencia potencial.

5. Conclusiones: las ideas expuestas al final serán una síntesis con el mismo orden de desarrollo del texto, indicando además las consecuencias, las implicaciones y recomendaciones a las que dio lugar el trabajo, y los interrogantes

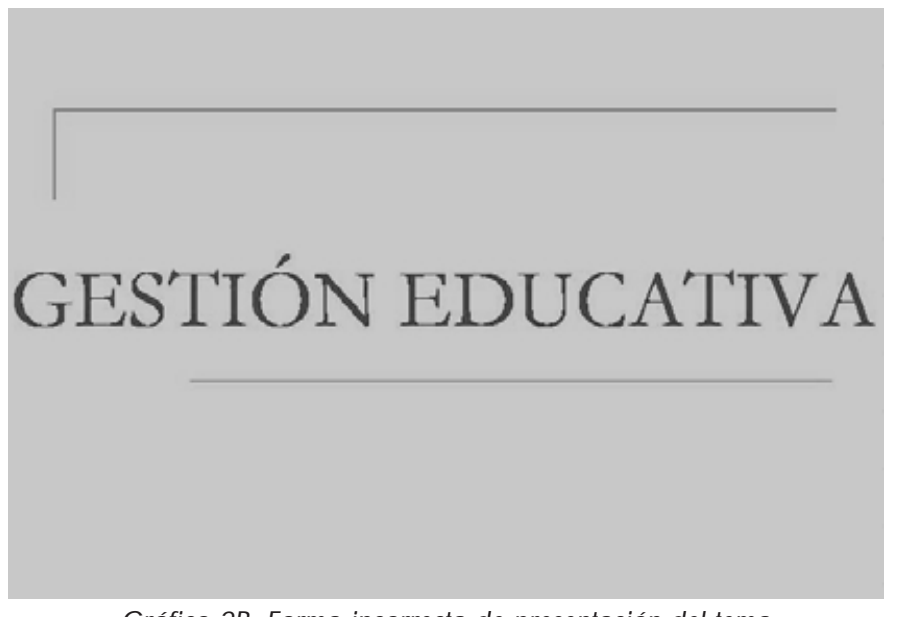

Gráfico 2B: Forma incorrecta de presentación del tema que se pudieran derivar de esta investigación y que aún queden sin responder.

6. Bibliografía recomendada: proporcionar a los oyentes las fuentes biblio-hemerográficas y electrónicas principales en las que se basó la información.

7. El orador debe controlar en todo momento los movimientos rápidos al señalar puntos de las diapositivas. Si se usa un mouse, debe vigilarse cuidadosamente no marear al auditorio desplazando el cursor o puntero erráticamente. Las personas sólo pueden fijar su atención si el desplazamiento es muy lento y sólo cuando sea necesario remarcar algo.

\section{Elección del hardware y el software}

\section{Software}

A continuación se enumeran los programas más conocidos $\mathrm{y}$ utilizados para elaborar presentaciones electrónicas en computadores compatibles:

\section{Adobe Persuasion (Adobe Systems Inc.)} Corp.)

2. Asap (Software Publishing

3. Astound for Windows (Gold Disk Inc.)

4. Compel (Asymetrix Corp.)

5. Corel Presents (Corel Corp.) 


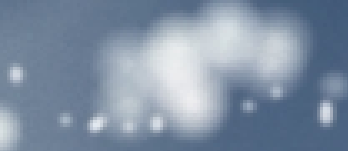

$+$

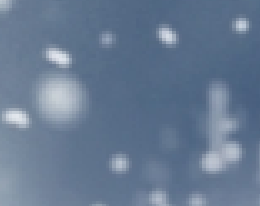

$\mathbf{e}$

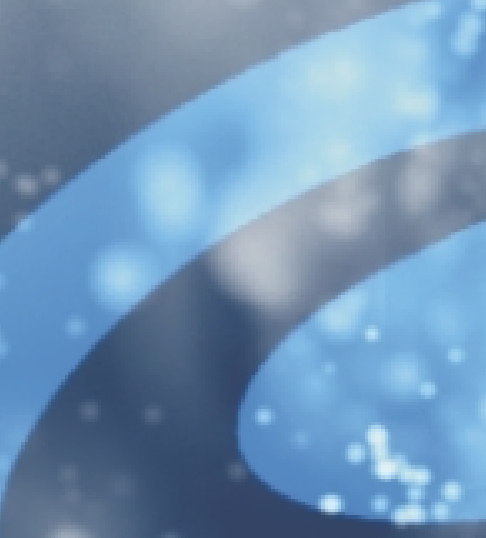

Un universo de información

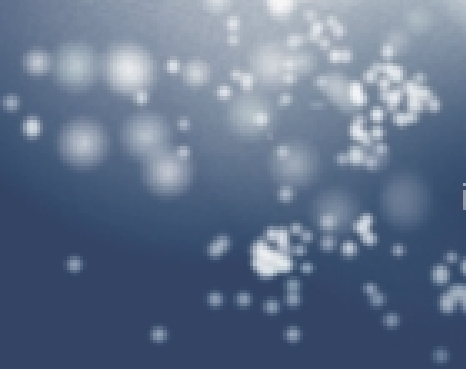

Hoy en día, Internet es el presente y futuro en el contexto general de los sistemas de información y gestión del conocimiento. Ahora es el momento de consolidar el potencial de su biblioteca.

SIRSI es pionera en sistemas de gestión de información

y tecnología para bibliotecas, archivos y centros de documentación. En SIRSI desarrollamos y facilitamos a nuestros clientes las herramientas más innovadoras $\mathrm{y}$ todos los servicios necesarios para que éstos puedan aportar a sus usuarios información y conocimiento desde cualquier fuente, en cualquier momento y lugar.

Unicorn, el sistema integrado de gestión bibliotecaria de SIRSI, aporta a los bibliotecarios una infraestructura de gestión global para controlar todos los aspectos diferenciadores de su biblioteca y facilitar e incrementar la eficiencia en el servicio al usuario final.

iBistro es la biblioteca electrónica de SIRSI que une las características mas innovadoras a las clásicas funcionalidades del catálogo público - OPAC: reseñas, información bibliotecaria, técnicas avanzadas de búsqueda y personalización, integración de fuentes de información internas y externas a la biblioteca...

\section{Ponemos el universo del conocimiento en sus manos}

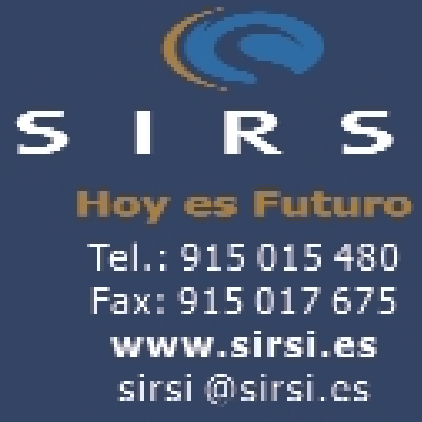


6. Harvard Graphics for Windows (Software Publishing Corp.)

7. Lotus Freelance Graphics (Lotus Development Corp.)

8. Lotus ScreenCam (Lotus)

9. Microsoft PowerPoint (Microsoft)

\section{Presentations (Novell Inc.)}

En algunas circunstancias, como es el caso de talleres o cursos, el investigador necesitará efectuar una presentación electrónica con cierta interactividad, usando tablas, vídeos o gráficos que se despliegan o muestran al tocar algún lugar especial de la pantalla. Todo esto se denomina interactividad multimedial y para ello es necesario emplear programas de autoría que generan un producto final interactivo, como los siguientes:

\section{Authorware (Macromedia)}

2. Everest Authoring System (Intersystem Concept)

\section{IconAuthor (Aimtech)}

4. ImageQ (Image North Technologies)

5. Macromedia Director (Macromedia)

6. MediaVerse (Looking Glass Software)

7. Multimedia Toolbox: CBT Edition (Asymetrix)

8. Media Objects (Oracle)

\section{Quest (Allen Communica- tions)}

La elección de cualquiera de estos programas estará bajo el criterio del expositor, no obstante, el más extendido es Microsoft PowerPoint $\AA$.

\section{Hardware}

Una vez armada la presentación, hace falta seleccionar las herramientas para la visualización de las imágenes. Esta es una parte importante para obtener el máximo éxito en el lugar programado.

Se recomienda tener en cuenta las características expuestas en la tabla 1 al seleccionar el proyector, según el tipo de sala. Brillo, resolución y peso son los tres aspectos principales a considerar.

El peso es una característica importante en el caso de que se hagan presentaciones fuera del lugar de trabajo, pero no lo es con proyectores que van a estar fijos en un auditorio, aula de clase o sala de juntas.

El brillo (que se mide en lúmenes) es la intensidad de la luz que emite un proyector y varía en las tres configuraciones propuestas. A mayor cantidad de lúmenes menor será la necesidad de oscurecer la sala.

La resolución es el número de puntos (píxeles) que forman la imagen. La resolución más baja ac-

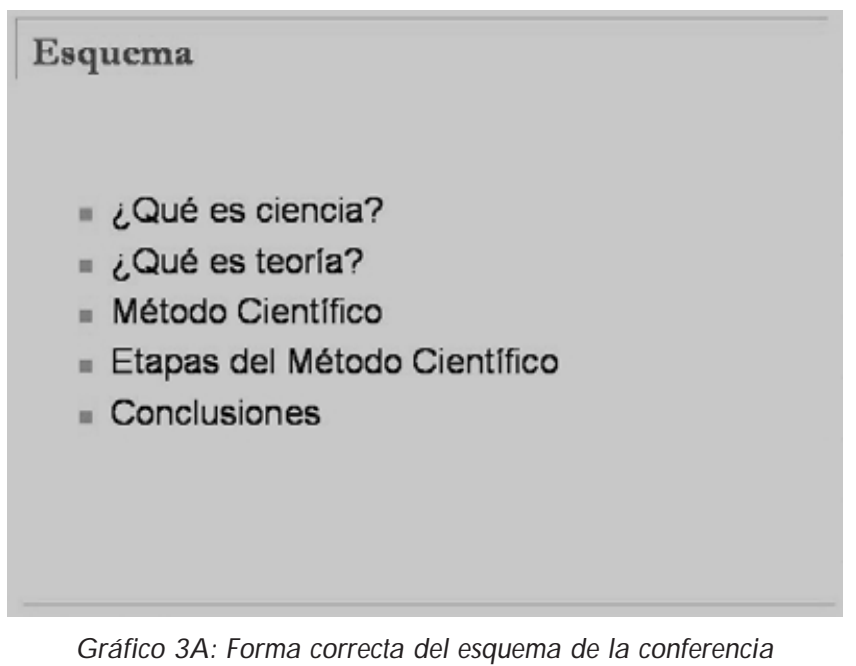

Gráfico 3A: Forma correcta del esquema de la conferencia tualmente es SVGA (Super video graphics array), en cuyo caso la imagen se forma en 480.000 puntos (800 horizontal x 600 vertical). Le sigue la $X G A$ (eXtended graphics array) que tiene 786.432 puntos (1.024 horizontal x 768 vertical). En vídeo y en PowerPoint no se aprecian diferencias en calidad de la imagen que justifiquen la mayor inversión. En cambio la diferencia es notoria cuando se manejan presentaciones a más de tres metros de distancia.

\section{«La comunica- ción de los re- sultados de una investigación es parte fundamen- tal de ella, y el multimedia, por utilizar elemen- tos innovadores en la exposición científica, es una de las for- mas más efecti- vas para cumplir ese propósito»}

Compresión. Es la capacidad de los proyectores de recibir una señal de mayor resolución y comprimirla a su resolución nativa. Por ejemplo, si se tiene un proyector con una resolución $S V G A$ (800x600), puede recibir una señal $X G A(1.024 \times 768)$ de un computador; sin embargo, de las 1.024 líneas sólo puede proyectar 800 , por lo cual debe descartar algunas o promediar dos líneas consecutivas para combinarlas en una sola y lo mismo en la otra dirección. En este caso las imágenes tienden a perder un poco su nitidez, por lo que se recomienda bajar la resolución de la computadora para que coincida con la del proyector, de manera que cada píxel de la computadora corresponda a un punto del proyector, lográndose una imagen muy nítida y clara. 


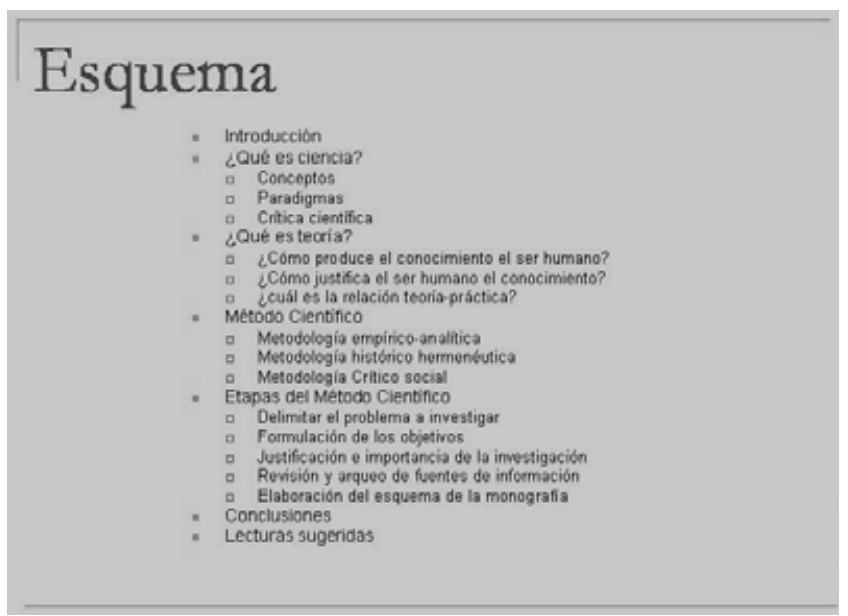

Gráfico 3B: Forma incorrecta del esquema de la conferencia

Zoom digital. En todos los proyectores actuales se puede ampliar o reducir el tamaño de la imagen girando manualmente el anillo de zoom que se encuentra detrás del anillo de enfoque, lo que logra un aumento de alrededor del $30 \%$. No obstante, algunos proyectores cuentan adicionalmente con zoom digital, mediante el cual se puede lograr un acercamiento, que consiste en seleccionar un rectángulo de la imagen y ampliarlo hasta abarcar toda la imagen.

Duración de la lámpara. Varía según el modelo y puede ser desde 1.500 hasta 3.000 horas. Depende de muchos factores: temperatura, humedad, número de veces que se enciende, golpes, vibraciones, variaciones de voltaje, etc., que pueden reducir su tiempo de vida.

Otros factores importantes al decidir la compra de un proyector son el control de mouse y la posibilidad de contar con un apuntador láser.

\section{Conclusiones}

La comunicación de los resultados de una investigación es una parte fundamental, casi su razón de ser, y el multimedia, por utilizar elementos innovadores en la exposición científica, es una de las formas más efectivas para cumplir ese propósito. Sin embargo esta efectividad depende de varios factores, siendo el principal la correcta planificación de la presentación en base a los objetivos que se quieran alcanzar.

Los recursos actuales del multimedia amplían las posibilidades en la difusión del conocimiento científico por su rapidez y el uso de información visual y auditiva simultánea. Además, ya es común en el ámbito científico que las presentaciones de congresos, coloquios y otros eventos se coloquen, posteriormente, en páginas web, lo que da cuenta de su capacidad para difundir el conocimiento por sí mismas, sin necesidad de la presencia del expositor, lo que hace posible que un público cada vez mayor acceda a la información científica sin limitaciones de espacio y tiempo.

Se recomienda cuidar los aspectos tratados a lo largo de este artículo a fin de mostrar a la audiencia una presentación electrónica ligera que a la vez de estimular sus sentidos, facilite la comprensión del mensaje científico y por ende contribuya al desarrollo de la ciencia.

\section{Bibliografía}

Barrancos, Patricio; Scavini de Lanari, Aurora. "La información científica: acceso y difusión”. En: Barrancos, Money. Operatoria Dental. Buenos Aires: Editorial Médica Panamericana SA, enero de 1999, pp. 1123-1159. Isbn 84-7903-371-1.

Cabero, Julio; Gisbert, Mercè. Materiales formativos multimedia en la Red. Guía práctica para su diseño. España: Secretariado de Recursos Audiovisuales y Nuevas Tecnologías. Universidad de Sevilla y Universitat Rovira i Virgili, 2002, Isbn 84-95454-68-8.

Collin, S. M. H. Diccionario de multimedia. Santafé de Bogotá: McGraw-Hill Interamericana SA, 1996, Isbn 0-948549-69-6.

Poole, Bernard. Tecnología Educativa. Bogotá: McGraw-Hill Interamericana SA, 2001, Isbn 958-41-0185-4.

St.-Pierre, Armand; Kustcher, Nathalie. Pedagogía e Internet. México: Editorial Trillas, 2001, Isbn 2-89416-115-8.

\section{Norelkys Espinoza Matheus y Ángel G. Rincón García}

Departamento de Investigación, Facultad de Odontología, Universidad de Los Andes.

Calle 24 entre Avenidas 2 y 3. Piso 1. Mérida, Venezuela.

Tel. y fax: +58-274-2402379.

norelkys@ula.ve

rinconga@ula.ve

\begin{tabular}{|c|c|c|c|c|c|c|c|}
\hline & Brillo & Peso & Resolución & Compresión & $\begin{array}{l}\text { Zoom } \\
\text { digital }\end{array}$ & Lámpara & $\begin{array}{l}\text { Control remoto y } \\
\text { función de mouse }\end{array}$ \\
\hline $\begin{array}{c}\text { Sala pequeña con poca luz y } \\
\text { audiencia máxima de } 50 \\
\text { personas }\end{array}$ & $\begin{array}{c}1000 \mathrm{a} \\
1800 \\
\text { lúmenes }\end{array}$ & $1 \mathrm{a} 3 \mathrm{Kg}$ & $800 \times 600$ SVGA & $\begin{array}{c}1024 \times 768 \times G A \\
1280 \times 1024 \text { SXGA } \\
\delta \\
1600 \times 1200 \text { UXGA }\end{array}$ & Si & $\begin{array}{c}2000 \text { a } \\
3000 \\
\text { horas }\end{array}$ & Si \\
\hline $\begin{array}{c}\text { Salones grandes con iluminación } \\
\text { ambiental baja, y capacidad de } \\
\text { hasta } 500 \text { personas }\end{array}$ & $\begin{array}{c}1200 \text { a } \\
2000 \\
\text { lúmenes }\end{array}$ & $\begin{array}{l}2.2 \mathrm{a} \\
2.6 \mathrm{Kg}\end{array}$ & $\begin{array}{c}800 \times 600 \text { SVGA ó } \\
1024 \times 768 \times G A\end{array}$ & $\begin{array}{r}1024 \times 768 \times \text { XGA ó } \\
1280 \times 1024 \text { SXGA }\end{array}$ & Si & $\begin{array}{l}2000 \\
\text { horas }\end{array}$ & Sí \\
\hline $\begin{array}{c}\text { Gran auditorio, con capacidad } \\
\text { máxima de } 1.000 \text { personas, y } \\
\text { mucha iluminación }\end{array}$ & $\begin{array}{c}4000 \\
3200 \text { o } \\
2500 \\
\text { lúmenes }\end{array}$ & $\begin{array}{c}6.8 \mathrm{a} \\
3.6 \mathrm{Kg}\end{array}$ & $\begin{array}{c}1024 \times 768 \\
X G A\end{array}$ & $\begin{array}{c}1280 \times 1024 \text { SXGA } \\
\text { ó } 1600 \times 1200 \\
\text { UXGA }\end{array}$ & Si & $\begin{array}{l}1500 \text { a } \\
2000 \\
\text { horas }\end{array}$ & Sí \\
\hline
\end{tabular}

Tabla 1. Aspectos a considerar en la elección del proyector de acuerdo con el tipo de auditorio 